\title{
Calculation of the Tafel slope and reaction order of the oxygen evolution reaction between pH 12 and pH 14 for the adsorbate mechanism
}

Denis Antipin, Marcel Risch*

Nachwuchsgruppe Gestaltung des Sauerstoffentwicklungsmechanismus, Helmholtz-Zentrum

Berlin für Materialien und Energie GmbH, Hahn-Meitner Platz 1, 14109 Berlin, Germany

*marcel.risch@helmholtz-berlin.de

\begin{abstract}
Despite numerous experimental and theoretical studies devoted to the oxygen evolution reaction, the mechanism of the OER on transition metal oxides remains controversial. This is in part owed to the ambiguity of electrochemical parameters of the mechanism such as the Tafel slope and reaction orders. We took the most commonly assumed adsorbate mechanism and calculated the Tafel slopes and reaction orders with respect to $\mathrm{pH}$ based on microkinetic analysis. We demonstrate that number of possible Tafel slopes strongly depends on a number of preceding steps and surface coverage. Furthermore, the Tafel slope becomes $\mathrm{pH}$ dependent when the coverage of intermediates changes with $\mathrm{pH}$. These insights complicate the identification of a rate-limiting step by a single Tafel slope at a single $\mathrm{pH}$. Yet, simulations of reaction orders complementary to Tafel slopes can solve some ambiguities to distinguish between possible rate-limiting steps. The most insightful information can be obtained from the low overpotential region of the Tafel plot. The simulations in this work provide clear guidelines to experimentalists for the identification of the limiting steps in the adsorbate mechanism using the observed values of the Tafel slope and reaction order in $\mathrm{pH}$-dependent studies.
\end{abstract}

\section{Introduction}

Electrochemical water splitting is a promising approach to store excess energy in the form of hydrogen bonds [1-3]. It comprises the hydrogen evolution reaction $\left(4 \mathrm{H}_{2} \mathrm{O}+4 \mathrm{e}^{-} \rightarrow 2 \mathrm{H}_{2}+\right.$ $4 \mathrm{OH}^{-}$; in alkaline media) and oxygen evolution reaction $\left(4 \mathrm{OH}^{-} \rightarrow \mathrm{O}_{2}+2 \mathrm{H}_{2} \mathrm{O}+4 \mathrm{e}^{-}\right.$, also in alkaline media). Latter reaction is known as a bottleneck in total efficiency due to it sluggish kinetics [4-6]. Despite numerous studies devoted to the OER, the mechanism of this reaction remains controversial due to lack of direct experimental evidence. This is mainly caused by the fact that oxygen evolution reaction is a complex process that requires the transfer of four electrons and four protons. Most of our knowledge about likely mechanisms is obtained from theoretical works, either by density functional theory or kinetic modeling or a combination of both [7-18]. The $\mathrm{pH}$ dependence of the calculated properties has thus far received little attention.

Insight into the mechanism of OER can be gained by evaluating the Nernst slope $v=$ $(\partial \mathrm{E} / \partial \mathrm{pH})_{\log i}$, the Tafel slope $\mathrm{b}=(\partial \mathrm{E} / \partial \log i)_{\mathrm{pH}}$, and the reaction order with respect to $\mathrm{pH} \rho=$ $(\partial \log i / \partial \mathrm{pH})_{\mathrm{E}}$ that are related as $[19,20]$ : 


$$
\left(\frac{\partial E}{\partial p H}\right)_{\log i}=-\left(\frac{\partial E}{\partial \log i}\right)_{p H} \times\left(\frac{\partial \log i}{\partial p H}\right)_{E}
$$

These partial derivatives are the key parameters of electrochemical reaction kinetics. Their values may depend on the overpotential and $\mathrm{pH}$. Most commonly, the mechanistic analysis is focused on the evaluation of the Tafel slope. It is applied to the Faradaic region of the obtained voltammograms or to chronoamperometry, where the process of interest (OER in our case) occurs. Later, the observed Tafel slopes can be compared to simulated or calculated ones to elucidate differences in the mechanism $[20,21]$. However, different observed Tafel slopes for similar materials or the same slope for different catalysts are insufficient to uniquely assign the rate-limiting step and the mechanistic sequence $[20,22,23]$.

In this work we calculated two key mechanistic parameters of OER by microkinetic analysis, namely the Tafel slope and reaction order with respect to $\mathrm{pH}$. They were calculated specifically for the adsorbate mechanism $[11,12,24]$. The calculated values and observable Tafel slopes strongly depended on the choice of the resting state and on the kinetic constants as well as on $\mathrm{pH}$ in some cases. Finally, we identify trends in the simulated data to provide guidelines for the assignment of the most likely rate-liming step based on the Tafel slope and reaction order.

\section{Methods}

The mechanistic parameters of Tafel slope and reaction order were calculated by microkinetic analysis [25]. In this work, it was based on basic electrochemical equations and expressions for current density, reaction rate and kinetic constants.

Current density of electrochemical reaction can be written as

$$
j=I / A=n \cdot F \cdot r
$$

where $\mathrm{n}$ - number of electrons involved; $\mathrm{F}$ - Faradaic constant ( $=96500 \mathrm{C} / \mathrm{mol}) ; \mathrm{A}$ - surface area of the catalyst; $r$ - reaction rate.

The reaction rate can be described by the following equation:

$$
r=k_{+i /-i} \cdot a_{j} \cdot \theta_{k}
$$

where $k_{i /-i}-$ kinetic constant of the direct/reverse reaction; $a_{j}$ - activity of involved species $\left(\mathrm{OH}, \mathrm{H}_{2} \mathrm{O}\right.$ or $\left.\mathrm{O}_{2}\right) ; \theta_{k}$ - surface coverage.

For all simulations, the activity of water in aqueous solution $\left(a_{\mathrm{H} 2 \mathrm{O}}\right)$ was equal to 1 and activity of dissolved oxygen $\left(a_{\mathrm{O}_{2}}\right)$ was assumed to be 0.001 [26]. Specifically, for Tafel analysis a hydroxide activity of $a_{O H}=1$ was used, corresponding to $\mathrm{pH}=14$. For analysis of the reaction order, the hydroxide activity ranged from 0.01 to 1 (corresponding to $\mathrm{pH} 12-14$ ) to stay in the alkaline regime.

The expression for the kinetic constant depends on the nature of the step. For electrochemical steps,

$$
k_{+i}=k_{+i}^{0} \cdot e^{(1-\alpha) \cdot f \cdot \eta}-\text { for the forward reaction; }
$$




$$
k_{-i}=k_{-i}^{0} \cdot e^{-\alpha \cdot f \cdot \eta}-\text { for the backward reaction, }
$$

where $\alpha$-transfer coefficient; $f=R T / F ; \mathrm{R}$ - universal gas constant $\left(=8.314 \mathrm{~J} \mathrm{~mol}^{-1} \mathrm{~K}\right) ; \mathrm{T}-$ temperature in $\mathrm{K} ; \mathrm{F}$ - Faraday constant; $\eta=E_{a p p l}-E^{0}$-overpotential, where $E^{0}$ is the thermodynamic equilibrium potential [27]. Here, we use $\mathrm{E}^{0}=0.40 \mathrm{~V}$ (standard potential of the OER at $\mathrm{pH}$ 14).

The expression for chemical steps is

$$
k_{+i /-i}=k_{+i /-i}^{0}
$$

In our analysis, the transfer coefficient $\alpha$ was set equal to 0.5 , unless otherwise stated. We also assumed clearly greater backward kinetic constants as compared to the forward ones $\left(k_{-i}^{0} \gg k_{i}^{0}\right)$. With this assumption, all steps prior to RLS do not happen simultaneously and all possible values for mechanistic parameters can be observed.

Combining Eqs. 2-6, we formulate the final expressions for the current density:

$$
\begin{aligned}
& j=n \cdot F \cdot k_{+i}^{0} \cdot e^{(1-\alpha) \cdot f \cdot \eta} \cdot a_{j} \cdot \theta_{k}-\text { for forward electrochemical step; } \\
& j=n \cdot F \cdot k_{-i}^{0} \cdot e^{-\alpha \cdot f \cdot \eta} \cdot a_{j} \cdot \theta_{k}-\text { for backward electrochemical step; } \\
& j=n \cdot F \cdot k_{+i-i}^{0} \cdot a_{j} \cdot \theta_{k}-\text { for chemical steps. }
\end{aligned}
$$

We assumed surface coverage of the $\mathrm{OH}$ intermediate equal to $\theta_{\mathrm{OH}}=1$ for the first step in the mechanism, meaning that the whole surface is fully covered with just one species. If there are some other species on the surface, in other words $\theta_{\mathrm{OH}} \neq 1$, it will affect only current density values, but not the observed Tafel slopes or reaction order. When further steps were considered to be rate-limiting, expressions for surface coverages were obtained through an assumption of pre-equilibrated previous steps. Thus, for all reactions prior to RLS, the reaction rates of the forward and backward steps are equal $\left(r_{i}=r_{-i}\right)$. Considering that the sum of all possible surface coverages is equal to 1 , we derived systems of equations for the surface coverage of all intermediates $\theta_{k}$. Solving these systems, expressions for all surface coverages were obtained and put in Eqs. 7 or 9 for the rate-limiting step. An example calculation for the first two steps can be found in the Supporting Information.

\section{Results and discussion}

\section{Introduction of the treated mechanism}

We calculated Tafel slope and reaction order with respect to $\mathrm{pH}$ by the microkinetic procedure outlined in the previous section and briefly summarized in Fig. 1. While Tafel slopes are often calculated assuming limiting a low or high coverage limit and further simplifications $[21,22,28]$, our approach explicitly includes the transitions between the limiting states in coverage that are also observable experimentally, e.g., as non-constant Tafel slopes in a given range of current or overpotential. 


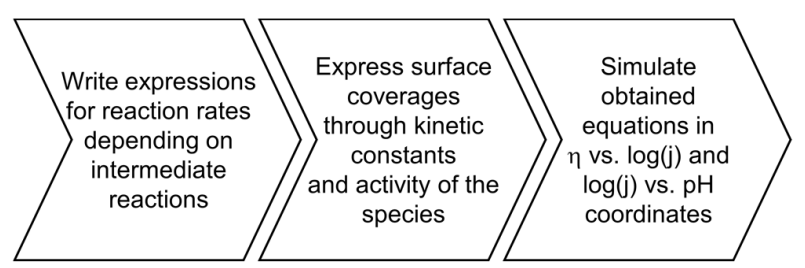

Fig. 1. Scheme of the simulation procedure with key steps.

Prototypical mechanisms of the OER have recently been proposed by us [29]. We focus in this report on the "adsorbate evolving mechanism (AEM)" or simply adsorbate mechanism, of which an early variant was proposed by Kobussen et al. [30]. The mechanism is popular in more recent DFT work $[7,11]$ and frequently assumed in experimental studies, e.g., in refs. $[31,32]$. It is also assumed for the reverse reaction of oxygen reduction [33,34]. The proposed steps in alkaline electrolytes are:

$$
\begin{array}{ll}
\text { M1 } & \underline{\mathrm{M}-\mathrm{OH}}+\mathrm{OH}^{-} \rightleftharpoons \underline{\mathrm{M}=\mathrm{O}}+\mathrm{H}_{2} \mathrm{O}+\mathrm{e} \\
\text { M2 } & \underline{\mathrm{M}=\mathrm{O}}+\mathrm{OH}^{-} \rightleftharpoons \underline{\mathrm{M}-\mathrm{OOH}}+\mathrm{e} \\
\mathrm{M3} & \underline{\mathrm{M}-\mathrm{OOH}}+\mathrm{OH}^{-} \rightleftharpoons \underline{\mathrm{M}-\mathrm{OO}^{-}}+\mathrm{H}_{2} \mathrm{O} \\
\text { M4 } & \underline{\mathrm{M}-\mathrm{OO}} \rightleftharpoons \underline{\mathrm{M}}+\mathrm{O}_{2}+\mathrm{e} \\
\text { M5 } & \underline{\mathrm{M}}+\mathrm{OH}^{-} \rightleftharpoons \underline{\mathrm{M}-\mathrm{OH}}+\mathrm{e}
\end{array}
$$

We here assumed that the catalysts have a hydroxylated surface in their resting state in alkaline electrolytes, which is supported experimentally by ambient pressure XPS studies [3537]. Our sequence is also used in experimental work by other groups [38-40]. Yet, it is in contradiction to other theoretical work $[7,10,41]$, where the surface is assumed to be bare (not hydroxylated), i.e., the sequence starts with $\mathrm{M} 5$ in our notation. This is a very important point as the choice of the resting state affects the calculated mechanistic parameters (Fig. S1 and Table S1). Here, all mechanistic parameters are calculated based on M1 - M5. These calculations rely on the coverage of surface states that are underlined in our notation.

Table 1. Values of kinetic constants used in the simulations as discussed in the text.

\begin{tabular}{|l|l|l|l|l|l|l|}
\hline \multirow{2}{*}{ Kinetic constant } & \multicolumn{7}{|c|}{ Rate-limiting step } \\
\cline { 2 - 7 } & $\mathbf{M 1}$ & $\mathbf{M 2}$ & $\mathbf{M}$ & $\mathbf{M 3}^{\prime}$ & $\mathbf{M 4}$ & $\mathbf{M 5}^{\prime}$ \\
\hline$k_{+1}$ & 1 & $10^{3}$ & $10^{3}$ & $10^{3}$ & $10^{3}$ & $10^{3}$ \\
\hline$k_{-1}$ & - & $10^{7}$ & $10^{7}$ & $10^{7}$ & $10^{7}$ & $10^{7}$ \\
\hline$k_{+2}$ & - & 1 & $10^{3}$ & $10^{3}$ & $10^{3}$ & $10^{3}$ \\
\hline$k_{-2}$ & - & - & $10^{10}$ & $10^{6}$ & $10^{10}$ & $10^{10}$ \\
\hline$k_{+3}$ & - & - & 1 & 1 & $2 \cdot 10^{12}$ & $2 \cdot 10^{12}$ \\
\hline$k_{-3}$ & - & - & - & - & $10^{12}$ & $10^{12}$ \\
\hline$k_{+4}$ & - & - & - & - & 1 & 10 \\
\hline$k_{-4}$ & - & - & - & - & - & $10^{12}$ \\
\hline$k_{+5}$ & - & - & - & - & - & 1 \\
\hline$k_{-5}$ & - & - & - & - & - & - \\
\hline
\end{tabular}


Our simulations are based on the kinetic constants found in Table 1. They are consistently and systematically chosen but arbitrary as very little experimental measurements are available [42-45]. The rate limiting step always has a rate of 1 (for simplicity) and all other steps are orders of magnitude faster. While the relative values are similar to experiments [42], the absolute values in Table 1 are consequently orders of magnitude higher. Thus, we use arbitrary units for the current density in all figures. The aim of this report is uncovering possible trends rather than an accurate calculation of the parameters for a given catalyst.

\section{Simulation of the Tafel slope}

There was a clear dependence of Tafel slope on surface coverage in our calculations. Fig. 2 shows simulated Tafel plots assuming the indicated steps $M 1$ to $M 5$ as rate-limiting. We first considered the deprotonation of an $\mathrm{OH}$-covered surface as limiting (M1), for which we found a single Tafel slope of $b_{M 1}=118 \mathrm{mV} \cdot \mathrm{dec}^{-1}$. The number of possible different Tafel slopes increased with a number of preceding steps. Moving to the $(M 2)$ reaction, we observed the two slopes of $40 \mathrm{mV} \cdot \mathrm{dec}^{-1}$ and $118 \mathrm{mV} \cdot \mathrm{dec}^{-1}$, depending on the dominant surface coverage of either $\mathrm{M}=\mathrm{O}$ (product of $\mathrm{M} 1$ ) or $\mathrm{M}-\mathrm{OOH}$ (product of $\mathrm{M} 2$ ). This means that the Tafel slopes depend on the pre-equilibria of preceding steps as also discussed elsewhere in the case of limiting coverages $[7,10]$. When the coverage of surface states was not constant, the Tafel slopes had intermediate values that strongly depend on the applied overpotential or current. Thus, a transition between two constant Tafel slopes in an experiment indicated that the dominant surface coverage changed. The overpotential at which the transition was observed depended on the choice of the kinetic constants (Fig. 2c vs 2d) as discussed further below. The third step (M3) in our sequence was chemical, which resulted in an infinite Tafel slope $b_{M 3}=$ $\infty \mathrm{mV} \cdot \mathrm{dec}^{-1}$ at high overpotentials (Fig. 2c). Infinite Tafel slopes are not found experimentally, however values above $200 \mathrm{mV} \cdot \mathrm{dec}^{-1}$ can be found in literature for $\mathrm{Cu}$ meshes or Pt plates $[46,47]$. The latter steps $M 4$ and $M 5$ produced complicated plots with many Tafel slopes and transitions (Fig. 2e,f). However, these cases are experimentally less relevant as usually, early RLS are assumed and supported by experimental data of electrocatalysts $[42,48,49]$. In particular, the expected Tafel slopes at low overpotential below about $30 \mathrm{mV} \cdot \mathrm{dec}^{-1}$ are rarely reported (Fig. S2a and recent reviews in refs. [50-53]).

The observation of multiple Tafel slopes depended strongly on the choice of the kinetic constants. We illustrated this for the case where M3 is the RLS (Fig. 2c,d). For this step, we used the same values for kinetic constants except $k_{-2}$. It is $10^{5}$-fold lower for $M 3^{\prime}$ (Table 1 ) and resulted in lower values of $\theta_{0}$, a narrowing of the coverage distribution as function of overpotential and a shift of the maximal coverage to a different overpotential (here a lower one; blue curves in Fig. $2 c, d$ ). The latter choice of kinetic constants means that $\underline{M=O}$ transforms into $\underline{\mathrm{M}-\mathrm{OOH}}$ much faster so that a surface fully covered with the $\underline{\mathrm{M}=\mathrm{O}}$ surface state cannot be observed. In other words, the overpotential range, for which a Tafel slope of $b_{M 3}=$ $59 \mathrm{mV} \cdot \mathrm{dec}^{-1}$ (O-O bond formation from $\underline{\mathrm{M}=\mathrm{O}}$ to $\underline{\mathrm{M}-\mathrm{OOH}}$ ) is expected becomes so narrow that it cannot be resolved. The same arguments can be made for all other limiting steps in the mechanism. In general, if the kinetic constants of the forward reaction $\left(k_{+i}\right)$ were faster than that of the backward reaction $\left(k_{-i}\right)$ then the changes in surface state were negligible and our plot reduced to the high overpotential/current limit that is either $118 \mathrm{mV} / \mathrm{dec}$ (assuming $\alpha=$ 0.5 ) for limitation by an electrochemical and infinite for a chemical step (Fig. S3 and Table S2). 
This scenario was proposed based on experiments for NiFe LDH [42] but not for Sb-doped $\mathrm{SnO}_{2}, \mathrm{PbO}_{2}$ and boron doped diamond, arguably much worse catalysts for the OER [43]. Thus, we show and discuss the more general result with $k_{+1}<k_{-1}$ with the caveat that not all Tafel slopes calculated herein may be experimentally observed on all electrocatalysts.
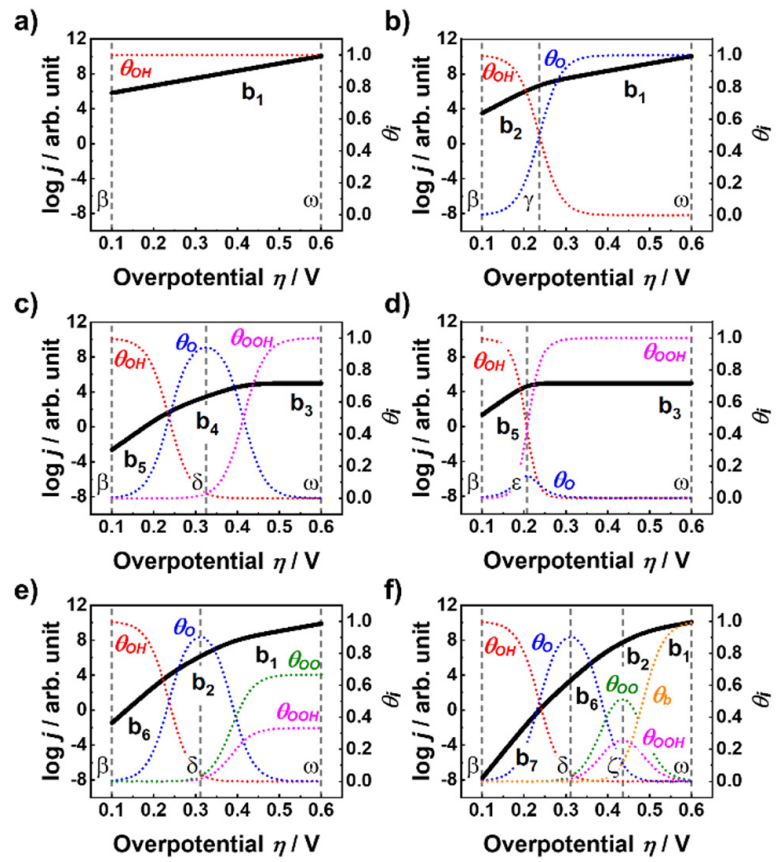

Fig. 2. Simulated Tafel plots assuming the RLS of (a) $M 1$, (b) $M 2$, (c) $M 3$, (d) $M 3^{\prime}$, (e) $M 4$ and (f) $M 5$. M3 and $M 3^{\prime}$ have the same RLS but were simulated with different sets of kinetic constants found in Table 1 . All simulations use a transfer coefficient of $\alpha=0.5$. The obtained Tafel slopes are denoted as: $b_{1}=118 \mathrm{mV} \cdot \mathrm{dec}^{-1}, \mathrm{~b}_{2}=40 \mathrm{mV} \cdot \mathrm{dec}^{-1}$, $b_{3}=\infty \mathrm{mV} \cdot \mathrm{dec}^{-1}, \mathrm{~b}_{4}=60 \mathrm{mV} \cdot \mathrm{dec}^{-1}, \mathrm{~b}_{5}=30 \mathrm{mV} \cdot \mathrm{dec}^{-1}, \mathrm{~b}_{6}=24 \mathrm{mV} \cdot \mathrm{dec}^{-1}, \mathrm{~b}_{7}=17 \mathrm{mV} \cdot \mathrm{dec}^{-1} \cdot \beta$ to $\omega$ denote potentials of interest that are analyzed further in other figures. Dataset in ref. [54].

\section{Effect of the transfer coefficient on the Tafel slope}

Another important parameter that affects Tafel slope is the transfer coefficient. In general, the anodic transfer coefficient is defined as [55]

$$
\alpha=\frac{R T}{F} \times\left(\frac{d \ln j_{a}}{d E}\right) .
$$

The OER is an entirely anodic reaction with high overpotential, which allows neglecting the contribution of the cathodic transfer coefficient. By definition, $\alpha$ is linked with the Tafel slope, which is defined as mentioned above as

$$
b=\left(\frac{\partial E}{\partial \log i}\right)_{p H}=\frac{R T}{\alpha F} .
$$

Whereas the transfer coefficient can be easily determined for an electrode reaction consisting of a single one electron transfer step, it becomes controversial for complex electrode reactions such as the OER. Currently the most common approach in kinetic investigations of 
electrode processes is to ascribe $\alpha$ an arbitrary value of 0.5 , both theoretical $[7,10]$ and experimental $[7,56]$ studies, which results in associated Tafel slopes of $118,59,40 \mathrm{mV} \cdot \mathrm{dec}^{-1}$ and lower ones (Table 2, $\alpha=0.5$ ). However, recent studies suggest that the value of $\alpha$ can be higher $\sim 0.8-0.9$ [57,58]. Additionally, Tafel slopes that cannot be explained by $\alpha=0.5$ such as 80,90 and $>120 \mathrm{mV} \cdot \mathrm{dec}^{-1}$ have been reported in literature (Fig. S2b), which supports that $\alpha=$ 0.5 is only a special case among other possible values. This literature survey motivated us to simulate Tafel plots with different values of the transfer coefficient (Fig. 3). Here we used moderate values of $\alpha(0.25,0.5$ and 0.75 ; schematic reaction diagram in Fig. $3 a)$ to illustrate the expected trends in the Tafel plots.

a)

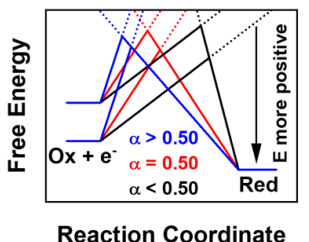

c)

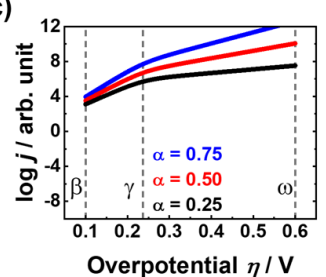

e)

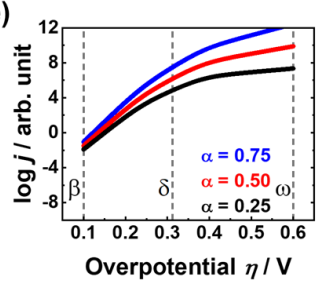

b)

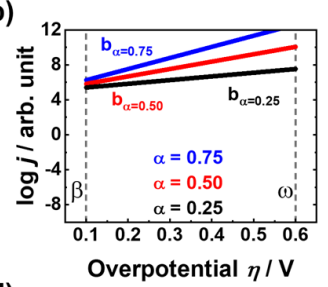

d)

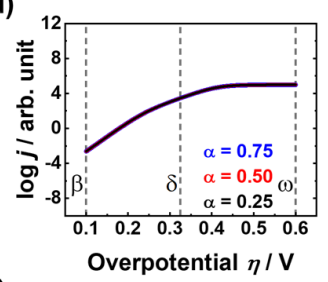

f)

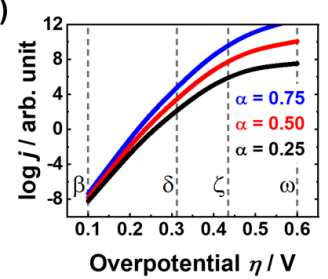

Fig. 3. Free energy diagram of $\mathrm{Ox}+\mathrm{e}=$ Red reaction with different transfer coefficient values (a) and simulated voltammogram plots with different values of $\alpha$ assuming the RLS of (b) M1, (c) M2, (d) M3, (e) M4 and (f) M5. Blue, red and black lines correspond to $\alpha$ values of $0.75,0.5$ and 0.25 respectively. All obtained values of the Tafel slope can be found in Table 2. Dataset in ref. [54]

The plots in Fig. 3 are qualitatively similar to those in Fig. 2. Three important observations were made. Firstly, the transition points between overpotential ranges of fixed Tafel slope were not affected by the choice of $\alpha$. Secondly, the values of the Tafel slopes were only affected by $\alpha$ for the electrochemical rate-limiting steps (Fig. 3b,c,e,f) but not for chemical rate-limiting states (Fig. 3d). It is no surprise since $\alpha$ by definition describes electrochemical charge transfer and is thus connected with current and potential. It can also be clearly seen in equations for electrochemical RLS (Eqs. 7,8) and absence of $\alpha$ for chemical RLS (Eq. 9). Thirdly, the value of the constant Tafel slopes clearly depended on the choice of $\alpha$, where $\alpha<0.5$ increased the Tafel slope and $\alpha>0.5$ decreased the Tafel slope. The largest difference can be observed for the highest value of the Tafel slope, i.e., $79 \mathrm{mV} \cdot \mathrm{dec}^{-1}$ for $\alpha=0.75$ and 236 $\mathrm{mV} \cdot \mathrm{dec}^{-1}$ for $\alpha=0.25$. For better numerical demonstration, we calculated all possible Tafel 
slopes using a common formula for multiple-electron reactions that connects Tafel slope, transfer coefficient and number of electrons involved (at $25^{\circ} \mathrm{C}$ ) [21]:

$$
b=\left(\frac{\partial E}{\partial \log i}\right)_{p H}=\frac{2.303 R T}{F} \times \frac{1}{n_{b}+\alpha n_{d}} \approx \frac{59 \mathrm{mV} \cdot \mathrm{dec}^{-1}}{n_{b}+\alpha n_{d}}
$$

All obtained values are summarized in Table 2, whose entries are color coded according to three categories: (i) improbable reaction steps in red, i.e., requiring more than 1 electron to be involved during the RLS; (ii) probable electrochemical RLS in blue; and (iii) probable chemical RLS in green. It can be clearly seen in Fig. 3 and Table 2 that the difference in Tafel slope with $\alpha$ decreased for smaller values of the Tafel slope, for more electrons were transferred before the RLS. Though they are distinct in the theoretical calculations, experimental verification might be impeded due to noise, small ranges with constant Tafel slope and other factors. Experimental errors of the Tafel slope can be as low as 1-2 $\mathrm{mV} \mathrm{dec}^{-1}$ [20] (one standard deviation, $68 \%$ confidence interval) or 3-5 $\mathrm{mV} \mathrm{dec}^{-1}$ [59] (two standard deviations, $95 \%$ confidence interval) for independent measurements of identical prepared electrodes. This indicates that the small deviations with $\alpha$ for more than $n=2$ are unlikely to be resolved experimentally in typical experimental studies. Our survey of reported Tafel slopes further supported the cutoff criterium of 2 transferred electrons before the RLS because Tafel slopes below $30 \mathrm{mV} \mathrm{dec}{ }^{-1}$ are rarely reported, while our literature survey showed clear maxima near $118,79,59$ and $40 \mathrm{mV} \mathrm{dec}^{-1}$ (Fig. S2), supporting a $\geq 0.5$.

Table 2. Variation of the Tafel slope with transfer coefficient $\alpha$.

\begin{tabular}{lllllll}
\hline Step & $\mathbf{n}$ & $\mathbf{n}_{\mathbf{b}}$ & $\mathbf{n}_{\mathbf{d}}$ & $\boldsymbol{\alpha}=\mathbf{0 . 2 5}$ & $\boldsymbol{\alpha}=\mathbf{0 . 5}$ & $\boldsymbol{\alpha}=\mathbf{0 . 7 5}$ \\
\hline M1 & 1 & 0 & 1 & $\mathbf{2 3 6}$ & $\mathbf{1 1 8}$ & $\mathbf{7 9}$ \\
M1 & 1 & 1 & 0 & $\mathbf{5 9}$ & $\mathbf{5 9}$ & $\mathbf{5 9}$ \\
M2 & 2 & 0 & 2 & 118 & 59 & 40 \\
M2 & 2 & 1 & 1 & $\mathbf{4 8}$ & $\mathbf{4 0}$ & $\mathbf{3 4}$ \\
M2 & 2 & 2 & 0 & $\mathbf{3 0}$ & $\mathbf{3 0}$ & $\mathbf{3 0}$ \\
\hline \hline M3 & 3 & 0 & 3 & 79 & 40 & 27 \\
M3 & 3 & 1 & 2 & 40 & 30 & 24 \\
M3 & 3 & 2 & 1 & $\mathbf{2 7}$ & $\mathbf{2 4}$ & $\mathbf{2 2}$ \\
M3 & 3 & 3 & 0 & $\mathbf{2 0}$ & $\mathbf{2 0}$ & $\mathbf{2 0}$ \\
M4 & 4 & 0 & 4 & 59 & 30 & 20 \\
M4 & 4 & 1 & 3 & 34 & 24 & 18 \\
M4 & 4 & 2 & 2 & 24 & 20 & 17 \\
M4 & 4 & 3 & 1 & $\mathbf{1 8}$ & $\mathbf{1 7}$ & $\mathbf{1 6}$ \\
M4 & 4 & 4 & 0 & $\mathbf{1 5}$ & $\mathbf{1 5}$ & $\mathbf{1 5}$ \\
\hline
\end{tabular}

$\mathrm{n}$ denotes total number of the electrons involved in the step, $\mathrm{n}_{b}-$ number of electrons before the RLS, $\mathrm{n}_{d}-$ number of electrons during the RLS. Red rows stand for highly improbable reactions, blue row - for electrochemical RLS, green row - for chemical RLS. A double bar indicates the boundary of experimental verification (see text).

In summary, there were several general trends in the Tafel slopes that must be highlighted. First, the lowest possible Tafel slope for the chosen RLS occured at the lowest overpotential/current region. It might cause some problems in experimental verification since 
catalysts with low overpotentials are required, at which catalytic currents may overlap with metal redox peaks. Second, all electrochemical steps approached $118 \mathrm{mV} \cdot \mathrm{dec}^{-1}$ slope, while all chemical steps approached an infinite slope as expected from the limiting cases [21]. These slopes can be accessed at high overpotential/current region and thus, can be obtained experimentally, often without interference by other redox peaks. These trends are also seen in the earlier microkinetic work of Shinagawa et al. [10] on the adsorbate mechanism, which is based on different assumptions of kinetic constants and a non-hydroxylated resting state. While the earlier work gives qualitatively similar trends with overpotential, the values of the constant Tafel slopes in the plots for each RLS (obtained only at $\alpha=0.5$ ) differ from our work. Lastly, the value of the Tafel slope depended on the transfer coefficient for electrochemical rate-limiting steps but did not affect the transition between regions of constant Tafel slope or Tafel slopes with chemical rate-limiting steps. The calculated differences in Tafel slope with the transfer coefficient may be too small to be resolved experimentally for more than two transferred electrons.

\section{Effect of $\mathrm{pH}$ on the Tafel slope}

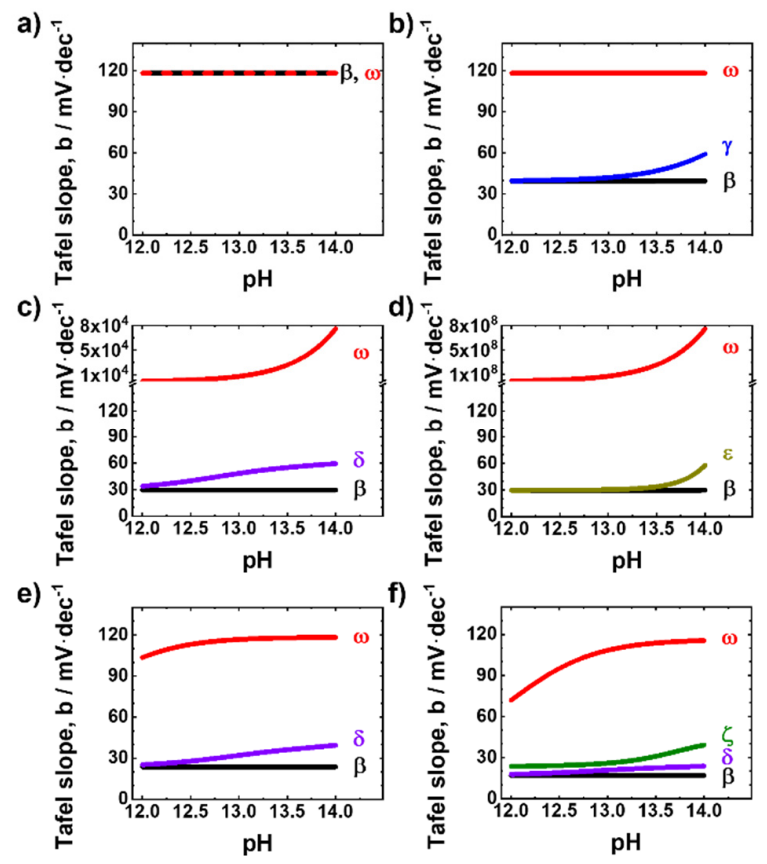

Fig. 4. Simulated Tafel slopes as function of $\mathrm{pH}$ at key potentials identified in Fig. 2 assuming the RLS of (a) M1, (b) $M 2$, (c) M3, (d) M3', (e) M4 and (f) M5. M3 and M3' have the same RLS but were simulated with different sets of kinetic constants found in Table 1. All simulations use a transfer coefficient of $\alpha=0.5$. Dataset in ref. [54].

The Tafel slope may depend on the pH (Fig. 4). To investigate this point, we simulated the $\mathrm{pH}$ dependence of the Tafel slope for selected overpotentials labeled $\beta$ to $\omega$. (Note that $\alpha$ is reserved for the transfer coefficient in this manuscript) Their values may be found in Fig 2 and 3. There was no change in coverage when $M 1$ was the RLS and the Tafel slope was $118 \mathrm{mVdec}^{1}$ between pH 12 and 14 (Fig. 4a). When $M 2$ was the RLS, $\beta$ and $\omega$ remained independent of $\mathrm{pH}$ but had different values (Fig. 4b). The Tafel slope at potential $\gamma$ was nearly constant for low $\mathrm{pH}$ 
but became $\mathrm{pH}$ dependent above $\mathrm{pH}$ 13. At potential $\delta$, the Tafel slope changed for each investigated $\mathrm{pH}$ with a sigmoidal shape, which could be seen when $M 3, M 4$ or M5 were the RLS (Fig. 4c,e,f). The trends of overpotentials $\varepsilon$ and $\xi$ matched those of potential $\delta$, i.e., constant at low $\mathrm{pH}$ and $\mathrm{pH}$-dependent for high $\mathrm{pH}$.

The $\mathrm{pH}$ trends in the Tafel slope can be rationalized by a change in the population of the intermediates. We considered $M 3$ as the RLS (Fig. 4c,d) to illustrate the effect of the surface population of intermediates on the $\mathrm{pH}$-dependence of the Tafel slope. At potential $\delta$, the coverage with intermediate $\underline{M-O}$ was at a maximum $\left(\theta_{0}=1.0\right)$, while the coverage of intermediates $\underline{\mathrm{M}-\mathrm{OH}}$ and $\underline{\mathrm{M}-\mathrm{OOH}}$ were at a minimum at $\mathrm{pH} 14$ (Fig. S4). Reducing the $\mathrm{pH}$ to $\mathrm{pH} 12$ lowered the population of $\underline{\mathrm{M}-\mathrm{O}}$ to $\theta_{\mathrm{O}}=0.2$. As the Tafel slope depends on the surface coverage, it became $\mathrm{pH}$-dependent through the change in the population of the intermediates with $\mathrm{pH}$. The comparison between Fig. $4 \mathrm{c}$ and $4 \mathrm{~d}$ illustrates that the $\mathrm{pH}$ trend fundamentally depended on the kinetic constants, which determined whether the coverage and Tafel slope changed in a given $\mathrm{pH}$ range (e.g., Fig. $5 \mathrm{c}$ or $\mathrm{pH}>13$ in Fig. $4 \mathrm{~d}$ ) or did not change (e.g., $\mathrm{pH}<13$ in Fig. 4d).

Even though analysis of the Tafel slope gives useful insights into mechanism of oxygen evolution reaction, it is not sufficient to uniquely ascertain the RLS. For instance, Tafel slope of $40 \mathrm{mV} \cdot \mathrm{dec}^{-1}$ can be observed for three different steps as RLS, namely M2, M4 and M5 (Fig. $2 b, e, f)$. In order to distinguish between these different possible RLS, further orthogonal mechanistic parameters need to be obtained. Tafel analysis can be performed as function of $\mathrm{pH}$ (i.e., a range of $\mathrm{OH}^{-}$activities) to obtain the reaction order with respect to $\mathrm{pH}$ or the reactant $\left(\mathrm{OH}^{-}\right.$in alkaline) from the slopes of $\log j \mathrm{vs.} \mathrm{pH}$ to gain complementary mechanistic insight.

\section{Simulation of the reaction order with respect to $\mathrm{pH}$}

We used microkinetic analysis to obtain the reaction order with respect to the overpotential on the scale of the standard hydrogen electrode (SHE) [19] because its value trends with the number of transferred hydroxide similar to the number of transferred electrons obtained from Tafel analysis. The reaction order is obtained as the derivative of the logarithmic current with respect to $\mathrm{pH}$ (Fig. S5), similarly to the derivatives that yield the simulated Tafel slopes above. Akin to Tafel slope simulations, we made an analysis of the reaction order for different transfer coefficient values for two extreme steps - M1 (Fig. S6a) and M5 (Fig. S6b). As it was mentioned above, the Tafel slope of electrochemical rate-limiting steps up to $\mathrm{n}=2$ is strongly connected with the transfer coefficient. In the plot of $\log \mathrm{j}$ vs. $\mathrm{pH}$, a change in the transfer coefficient affected the $\mathrm{y}$-axis intercept of the resulting trend of the current with $\mathrm{pH}$, but did not affect the slope regardless of the RLS. Thus, reaction order with respect to $\mathrm{pH}$ may be a perfect match to the Tafel slope that helps to mitigate the ambiguity introduced by the uncertainty in the transfer coefficient. 
a)

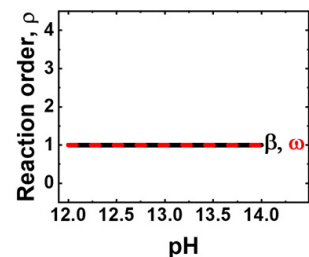

c)

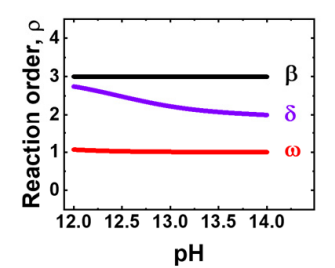

e)

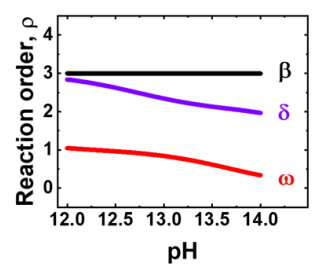

b)

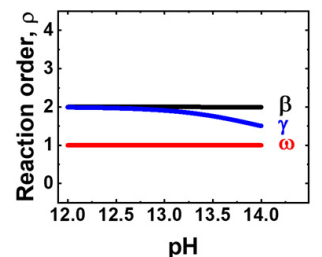

d)

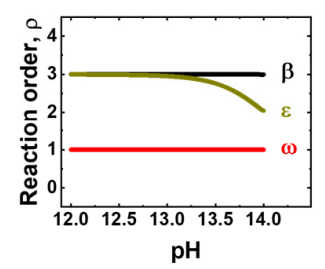

f)

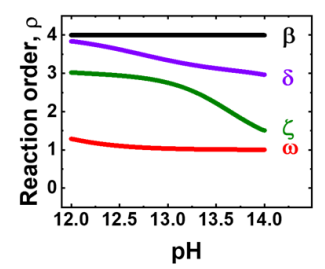

Fig. 5. Simulated reaction order $(\rho)$ plots assuming for selected key potentials in Fig. 2 assuming the RLS of (a) $M 1$, (b) M2, (c) M3 (d) M3', (e) M4 (e) and (f) M5 steps. M3 and M3' have the same RLS but were simulated with different sets of kinetic constants found in Table 1. Dataset in ref. [54]

Figure 5 shows the expected reaction orders for the potentials of interest defined in Fig. 2. We assume that steps M1-M5 were the RLS akin to the Tafel analysis above. Again, we considered deprotonation of the $\underline{\mathrm{M}-\mathrm{OH}}$ surface state $(M 1)$ as the first possible RLS. Analogous to the Tafel slope, we observed only one possible reaction order $\rho_{M 1}=1$ within the $\mathrm{pH}$ range. Assuming the second reaction (M2) as the RLS, we found two possible $\mathrm{pH}$ independent reaction orders, $\rho_{M 2 \omega}=1$ for high overpotential (labeled $\omega$ ) and $\rho_{M 2 \beta}=2$ for low overpotential (labeled $\beta$ ). At intermediate overpotentials, the reaction order was fractional and depended on $\mathrm{pH}$. This is again analogous to the observations of the Tafel slopes with $\mathrm{pH}$ (Fig. 4b). Moving to M3 as the RLS, the reaction order at high overpotentials (labeled $\omega$ ) retained the previous value of $\rho_{M 3 \omega}$ $=\rho_{\mathrm{M} 2 \omega}=1$, while the reaction order at low overpotential was $\rho_{\mathrm{M} 3}=3$, both independent of $\mathrm{pH}$. An intermediate reaction order of $\rho_{M 3} \delta=2$ is expected but barely reached at $\mathrm{pH} 14$ (Fig. $5 c)$. Instead, the reaction order was fractional and depended on the $\mathrm{pH}$. The sigmoidal shape of the trend and comparison with Fig. $5 \mathrm{~d}$ (i.e., a different set of kinetic constants) suggested that $\rho_{M 3 \delta}=\rho_{M 3 \beta}=3$ at low $\mathrm{pH}$. For the later RLS of $M 4$ and $M 5$ (Fig. 5e,f), the reaction order at low overpotential ( $\rho_{\mathrm{Mi} \beta}$ ) increased with the number of transferred $\mathrm{OH}^{-}$(up to 4 for $\mathrm{M5}$ ), while the reaction order depended on $\mathrm{pH}$ for higher overpotentials. According to our literature survey, reaction orders $\rho>2$ have not been reported yet. Mainly one can find reaction orders of either $\rho=1[19,20,56,60]$ or $\rho=2[61-64]$ or fractional values below 2 , such as $\rho=1.5[56]$ for first row transition metal oxides in alkaline electrolytes. This hints at an early RLS in experiments but cannot exclude a later RLS where the expected higher reaction order was not resolved. 
a)

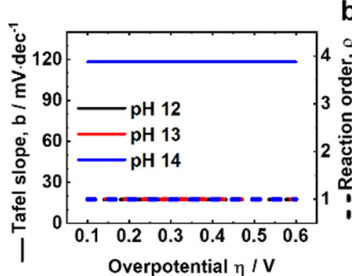

c)

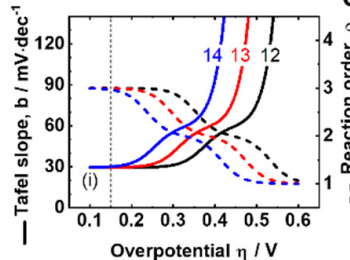

e)

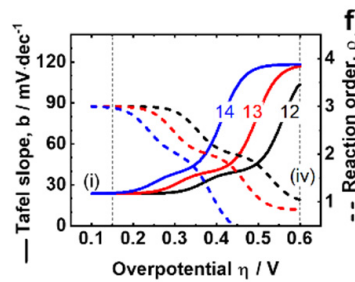

b)

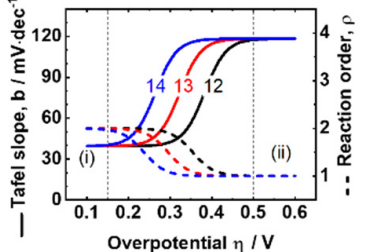

d)

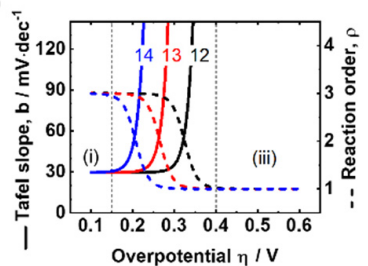

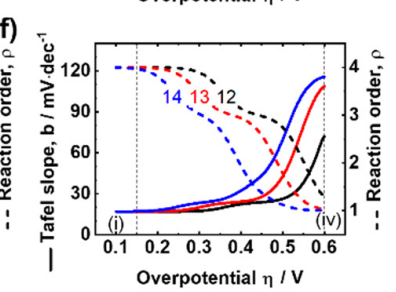

Fig. 6. Simulated Tafel slopes (left y-axis) and reaction order (right y-axis) as function of overpotential (E-E $\left.E^{0}\right)$ for $\mathrm{pH} 12,13$ and 14 the RLS of (a) M1, (b) M2, (c) M3 (d) M3', (e) M4 (e) and (f) M5 steps. M3 and M3' have the same RLS but were simulated with different sets of kinetic constants found in Table 1. $\alpha-\omega$ indicate potential regions with constant mechanistic parameters. Dataset in ref.[54].

\section{Synergy between Tafel slope and reaction order}

In order to investigate the complementary of the Tafel slope and reaction order, we plotted simulated Tafel slopes overlaid with the corresponding reaction orders as function of overpotential for $\mathrm{pH} \mathrm{12,13}$ and 14 (Fig.6). For $M 1$ as the RLS, both Tafel slope and reaction order were constant as expected from the above discussions (Fig. 6a). When M2 was the RLS, there were two overpotential regions labeled (i) and (ii) at the lowest and highest overpotentials, respectively, for which Tafel slope and reaction order were simultaneously constant (Fig. 6b). These are the overpotential ranges that can be meaningfully evaluated for mechanistic insight and to benchmark mechanisms. For intermediate overpotentials, both Tafel slope and reaction order changed as function of $\mathrm{pH}$. When $M 3$ is the RLS, three different combinations of Tafel slope and reaction order can be expected but, only one region of constant values (region (i) in Fig. 6c) was found at low overpotentials in our simulations where a second region is just outside the highest investigated overpotentials. Additionally, there was a very narrow overpotential region with the third combination which could not be clearly distinguished from the transition region with overpotential- and $\mathrm{pH}$ dependence. With the alternative set of kinetic constants for the same RLS, the intermediate combination vanished and the high overpotential Tafel slope and reaction order were constant (region (iii) in Fig. 6d). M4 and M5 as the RLS are similar to the case described for M3 where only the low overpotential region (i) gives access to constant Tafel slopes and reaction orders (Fig. 6e,f). It should be noted that the reaction order becomes zero for an electrochemical RLS after a chemical RLS at high overpotential and pH as can be seen in Fig. 6e. In summary, the most 
insightful region for mechanistic analysis can be found at low overpotential. Secondary information can be gained at high overpotential, particularly regarding whether the RLS is chemical or electrochemical. Experimentally, the product current of the evolved oxygen should be detected for reliable determination of the Tafel slope and reaction order, particularly at low overpotential where they may be in competition with metal redox peaks [65]. The high overpotential region may be inaccessible due to excessive bubble formation.

We now summarize our insights in a schematic catalytic cycle for the adsorbate mechanism (Fig. 7), where unique combinations of the Tafel slope and reaction order are highlighted. These unique combinations are found at low overpotential and $\mathrm{pH}$, while the secondary combinations can be identical to previous steps of the same type if resolved, e.g., M2 (and all other steps with an electrochemical RLS) behaved like $M 1$ at high overpotential, i.e., they exhibited the combination of $\rho=1$ and $b=118 \mathrm{mV} / \mathrm{dec}$. It means that only the last $\mathrm{OH}^{-}$transfer matters and all previous steps can be neglected in the calculation of the reaction order as proposed elsewhere [20]. The only chemically limiting step $M 3$ has distinct Tafel slopes from the electrochemically limited steps. Overall, we hope that our analysis and in particular the unambiguous assignments in Fig. 7 provide a benchmark for the identification of this mechanism in experimental studies.

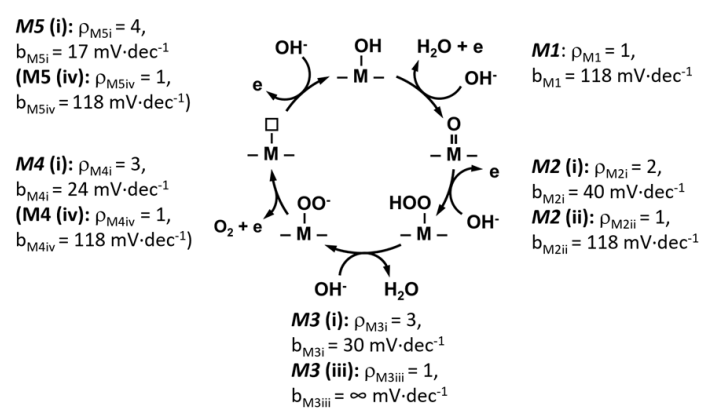

Fig. 7. Catalytic cycle for adsorbate mechanism with corresponding unique combinations of the Tafel slope and reaction order.

\section{Conclusions}

Two key mechanistic parameters were calculated using a microkinetic approach. We made our simulations for the commonly discussed adsorbate mechanism [11,12,24]. A hydroxylated surface was considered as the starting point in contrast to DFT and other microkinetic works based on empty sites [10].The simulated Tafel plots showed an increase of possible Tafel slopes with the number of preceding steps. Not all Tafel slopes may be observed depending on the kinetic constants, which in turn affected the population of intermediate surface states. If the surface coverage of a specific intermediate was low, then the corresponding Tafel slope might not be observed. When the surface coverage was not constant, the Tafel slope strongly depended on applied overpotential and $\mathrm{pH}$, which resulted in regions with no well-defined 
values of the slope. We further investigated the effect of the transfer coefficient on the value of the Tafel slope, which had its largest influence at high overpotential. We demonstrated that the RLS cannot be identified by a single Tafel slope. Instead, an additional mechanistic parameter was required to distinguish between possible rate-limiting steps and hereafter mechanisms. Complementary to Tafel slopes, we provided simulations of the reaction order with respect to $\mathrm{pH}$. We showed that this parameter is not affected by the transfer coefficient. We discussed that the most insightful information can be obtained from the low overpotential region, where the influence of the (often unknown) transfer coefficient was lowest and potential- as well as $\mathrm{pH}$-independent values of both the Tafel slope and reaction order were observed. Thus, knowing the maximum value of the reaction order accompanying by the Tafel slope at low overpotential made it possible to distinguish the RLS of the adsorbate mechanism. The main challenge is stabilizing those RLS over a large potential range to obtain small Tafel slope values experimentally. Nonetheless, our work provides clear guidelines to experimentalists for the identification of the RLS in the adsorbate mechanism using the observed values of the Tafel slope and reaction order.

\section{Acknowledgements}

This project has received funding from the European Research Council (ERC) under the European Union's Horizon 2020 research and innovation programme under grant agreement No. 804092.

\section{Conflict of Interest}

We declare no conflict of interest

\section{Data statement}

The data that support the findings of this study are openly available in Figshare at https://doi.org/10.6084/m9.figshare.17122220

\section{References}

[1] Armaroli N and Balzani V 2007 The Future of Energy Supply: Challenges and Opportunities Angew. Chemie Int. Ed. 46 52-66

[2] Balzani V, Bergamini G and Ceroni P 2015 Light: A Very Peculiar Reactant and Product Angew. Chemie Int. Ed. 54 11320-37

[3] Schlögl R 2016 Sustainable Energy Systems: The Strategic Role of Chemical Energy Conversion Top. Catal. 59 772-86

[4] Dau H, Limberg C, Reier T, Risch M, Roggan S and Strasser P 2010 The Mechanism of Water Oxidation: From Electrolysis via Homogeneous to Biological Catalysis 
ChemCatChem 2 724-61

[5] Steele B C H and Heinzel A 2001 Materials for fuel-cell technologies Nature 414 34552

[6] Tahir M, Pan L, Idrees F, Zhang X, Wang L, Zou J J and Wang Z L 2017 Electrocatalytic oxygen evolution reaction for energy conversion and storage: $A$ comprehensive review Nano Energy 37 136-57

[7] Mefford J T, Zhao Z, Bajdich M and Chueh W C 2020 Interpreting Tafel behavior of consecutive electrochemical reactions through combined thermodynamic and steady state microkinetic approaches Energy Environ. Sci. 13 622-34

[8] Rossmeisl J, Logadottir A and Nørskov J K 2005 Electrolysis of water on (oxidized) metal surfaces Chem. Phys. 319 178-84

[9] Geppert J, Kubannek F and Krewer U 2020 Microkinetic Modeling of the Oxygen Evolution Reaction (OER) on Hydrous Iridium Oxide during Dynamic Operation ECS Meet. Abstr. MA2020-01 1523

[10] Shinagawa T, Garcia-Esparza A T and Takanabe K 2015 Insight on Tafel slopes from a microkinetic analysis of aqueous electrocatalysis for energy conversion Sci. Rep. 5 121

[11] Man I C, Su H, Calle-Vallejo F, Hansen H A, Martínez J I, Inoglu N G, Kitchin J, Jaramillo T F, Nørskov J K and Rossmeisl J 2011 Universality in Oxygen Evolution Electrocatalysis on Oxide Surfaces ChemCatChem 3 1159-65

[12] Rossmeisl J, Qu Z-W, Zhu H, Kroes G-J and Nørskov J K 2007 Electrolysis of water on oxide surfaces J. Electroanal. Chem. 607 83-9

[13] Abidi N, Lim K R G, Seh Z W and Steinmann S N 2021 Atomistic modeling of electrocatalysis: Are we there yet? Wiley Interdiscip. Rev. Comput. Mol. Sci. 11 e1499

[14] Exner K S and Exner K S 2020 Recent Progress in the Development of Screening Methods to Identify Electrode Materials for the Oxygen Evolution Reaction Adv. Funct. Mater. $\mathbf{3 0} 2005060$

[15] Xiao H, Shin H and Goddard W A 2018 Synergy between Fe and Ni in the optimal performance of $(\mathrm{Ni}, \mathrm{Fe}) \mathrm{OOH}$ catalysts for the oxygen evolution reaction Proc. Natl. Acad. Sci. U. S. A. 115 5872-7

[16] George K, Khachatrjan T, van Berkel M, Sinha V and Bieberle-Hütter A 2020 Understanding the impact of different types of surface states on photoelectrochemical water oxidation: A microkinetic modeling approach ACS Catal. $1014649-60$

[17] Govind Rajan A and Carter E A 2020 Microkinetic model for $\mathrm{pH}$ - and potentialdependent oxygen evolution during water splitting on Fe-doped $\beta-\mathrm{NiOOH}$ Energy Environ. Sci. 13 4962-76

[18] Nishimoto T, Shinagawa T, Naito T and Takanabe K 2020 Microkinetic assessment of electrocatalytic oxygen evolution reaction over iridium oxide in unbuffered conditions J. Catal. $391435-45$ 
[19] Giordano L, Han B, Risch M, Hong W T, Rao R R, Stoerzinger K A and Shao-Horn Y 2016 PH dependence of OER activity of oxides: Current and future perspectives Catal. Today 262 2-10

[20] Köhler L, Ebrahimizadeh Abrishami M, Roddatis V, Geppert J and Risch M 2017 Mechanistic Parameters of Electrocatalytic Water Oxidation on LiMn2O4 in Comparison to Natural Photosynthesis ChemSusChem 10 4479-90

[21] Fletcher S 2009 Tafel slopes from first principles J. Solid State Electrochem. 13 537-49

[22] Doyle R L, Godwin I J, Brandon M P and Lyons M E G 2013 Redox and electrochemical water splitting catalytic properties of hydrated metal oxide modified electrodes Phys. Chem. Chem. Phys. 15 13737-83

[23] Bockris J O M and Otagawa T 1983 Mechanism of oxygen evolution on perovskites J. Phys. Chem. 87 2960-71

[24] Kobussen A G C and Broers G H J 1981 The oxygen evolution on La0.5Ba0.5CoO3 J. Electroanal. Chem. Interfacial Electrochem. 126 221-40

[25] Motagamwala A H and Dumesic J A 2020 Microkinetic Modeling: A Tool for Rational Catalyst Design Chem. Rev. 121 1049-76

[26] Xing W, Yin M, Lv Q, Hu Y, Liu C and Zhang J 2014 Oxygen Solubility, Diffusion Coefficient, and Solution Viscosity Rotating Electrode Methods Oxyg. Reduct. Electrocatal. 1-31

[27] Atkins P W, De Paula J and Keeler J 2018 Atkins' Physical Chemistry: Thermodynamics and Kinetics (Oxford University Press)

[28] Bockris J O 1956 Kinetics of Activation Controlled Consecutive Electrochemical Reactions: Anodic Evolution of Oxygen J. Chem. Phys. 24 817-27

[29] Antipin D and Risch M 2020 Trends of epitaxial perovskite oxide films catalyzing the oxygen evolution reaction in alkaline media J. Phys. Energy 232003

[30] Kobussen A G C and Broers G H J 1981 The oxygen evolution on La0.5Ba0.5CoO3. Theoretical impedance behaviour for a multi-step mechanism involving two adsorbates J. Electroanal. Chem. 126 221-40

[31] Harzandi A M, Shadman S, Nissimagoudar A S, Kim D Y, Lim H, Lee J H, Kim M G, Jeong H Y, Kim Y and Kim K S 2021 Ruthenium Core-Shell Engineering with Nickel Single Atoms for Selective Oxygen Evolution via Nondestructive Mechanism Adv. Energy Mater. 2003448

[32] Liu C, Qian J, Ye Y, Zhou H, Sun C J, Sheehan C, Zhang Z, Wan G, Liu Y S, Guo J, Li S, Shin H, Hwang S, Gunnoe T B, Goddard W A and Zhang S 2021 Oxygen evolution reaction over catalytic single-site $\mathrm{Co}$ in a well-defined brookite TiO2 nanorod surface Nat. Catal. 4 36-45

[33] Risch M 2017 Perovskite electrocatalysts for the Oxygen reduction reaction in alkaline media Catalysts 7 25-8

[34] Poux T, Bonnefont A, Ryabova A, Kéranguéven G, Tsirlina G A and Savinova E R 2014 Electrocatalysis of hydrogen peroxide reactions on perovskite oxides: experiment 
versus kinetic modeling Phys. Chem. Chem. Phys. 16 13595-600

[35] Newberg J T, Starr D E, Yamamoto S, Kaya S, Kendelewicz T, Mysak E R, Porsgaard S, Salmeron M B, Brown G E, Nilsson A and Bluhm H 2011 Formation of hydroxyl and water layers on MgO films studied with ambient pressure XPS Surf. Sci. 605 89-94

[36] Yamamoto S, Kendelewicz T, Newberg J T, Ketteler G, Starr D E, Mysak E R, Andersson K J, Ogasawara H, Bluhm H, Salmeron M, Brown G E and Nilsson A 2010 Water adsorption on $\alpha-\mathrm{Fe} 2 \mathrm{O} 3$ (0001) at near ambient conditions J. Phys. Chem. C 114 225666

[37] Stoerzinger K A, Hong W T, Crumlin E J, Bluhm H, Biegalski M D and Shao-Horn Y 2014 Water reactivity on the $\mathrm{LaCOO} 3$ (001) surface: An ambient pressure x-ray photoelectron spectroscopy study J. Phys. Chem. C 118 19733-41

[38] Suntivich J, May K J, Gasteiger H A, Goodenough J B and Shao-Horn Y 2011 A perovskite oxide optimized for oxygen evolution catalysis from molecular orbital principles Science (80-. ). 334 1383-5

[39] Mefford J T, Rong X, Abakumov A M, Hardin W G, Dai S, Kolpak A M, Johnston K P and Stevenson K J 2016 Water electrolysis on La1-xSrxCoO3- $\delta$ perovskite electrocatalysts Nat. Commun. 711053

[40] Wang L, Li H, Liu J, Lang X and Wang W 2021 Labile oxygen participant adsorbate evolving mechanism to enhance oxygen reduction in SmMn2O5with doublecoordinated crystal fields J. Mater. Chem. A 9 380-9

[41] Dong Y, Zhang P, Kou Y, Yang Z, Li Y and Sun X 2015 A first-principles study of oxygen formation over NiFe-layered double hydroxides surface Catal. Letters 145 1541-8

[42] Alobaid A, Wang C and Adomaitis R A 2018 Mechanism and Kinetics of HER and OER on NiFe LDH Films in an Alkaline Electrolyte J. Electrochem. Soc. 165

[43] García-Osorio D A, Jaimes R, Vazquez-Arenas J, Lara R H and Alvarez-Ramirez J 2017 The Kinetic Parameters of the Oxygen Evolution Reaction (OER) Calculated on Inactive Anodes via EIS Transfer Functions: • OH Formation J. Electrochem. Soc. 164 E3321-8

[44] Sonwalkar H S and Haram S K 2017 Kinetic Analysis of the Oxygen Evolution Reaction (OER) Performed with a Cobalt-Phosphate Electrocatalyst ChemistrySelect 2 3323-8

[45] Khadke P, Tichter T, Boettcher T, Muench F, Ensinger W and Roth C 2021 A simple and effective method for the accurate extraction of kinetic parameters using differential Tafel plots Sci. Reports 202111111 1-15

[46] Ranaweera C K, Zhang C, Bhoyate S, Kahol P K, Ghimire M, Mishra S R, Perez F, Gupta B K and Gupta R K 2017 Flower-shaped cobalt oxide nano-structures as an efficient, flexible and stable electrocatalyst for the oxygen evolution reaction Mater. Chem. Front. 1 1580-4

[47] Xiaoyan Hu, Xuemei Tian, Ying-Wu Lin and Zhonghua Wang 2019 Nickel foam and stainless steel mesh as electrocatalysts for hydrogen evolution reaction, oxygen evolution reaction and overall water splitting in alkaline media RSC Adv. 9 31563-71

[48] Li P, Duan X, Kuang Y, Li Y, Zhang G, Liu W and Sun X 2018 Tuning Electronic Structure 
of NiFe Layered Double Hydroxides with Vanadium Doping toward High Efficient Electrocatalytic Water Oxidation Adv. Energy Mater. 81703341

[49] Yeo B S and Bell A T 2011 Enhanced Activity of Gold-Supported Cobalt Oxide for the Electrochemical Evolution of Oxygen J. Am. Chem. Soc. 133 5587-93

[50] Yuan N, Jiang Q, Li J and Tang J 2020 A review on non-noble metal based electrocatalysis for the oxygen evolution reaction Arab. J. Chem. 13 4294-309

[51] Yu M, Budiyanto E and Tüysüz H 2021 Principles of Water Electrolysis and Recent Progress in Cobalt-, Nickel-, and Iron-Based Oxides for the Oxygen Evolution Reaction Angew. Chemie Int. Ed.

[52] Liu D, Zhou P, Bai H, Ai H, Du X, Chen M, Liu D, Ip W F, Lo K H, Kwok C T, Chen S, Wang S, Xing G, Wang $X$ and Pan H 2021 Development of Perovskite Oxide-Based Electrocatalysts for Oxygen Evolution Reaction Small 2101605

[53] Suen N-T, Hung S-F, Quan Q, Zhang N, Xu Y-J and Chen H M 2017 Electrocatalysis for the oxygen evolution reaction: recent development and future perspectives Chem. Soc. Rev. 46 337-65

[54] Antipin D and Risch M 2021 Calculation of the Tafel slope and reaction order of the oxygen evolution reaction between $\mathrm{pH} 12$ and $\mathrm{pH} 14$ for the adsorbate mechanism

[55] Guidelli R, Compton R G, Feliu J M, Gileadi E, Lipkowski J, Schmickler W and Trasatti S 2014 Defining the transfer coefficient in electrochemistry: An assessment (IUPAC Technical Report) Pure Appl. Chem. 86 245-58

[56] Negahdar L, Zeng F, Palkovits S, Broicher C and Palkovits R 2019 Mechanistic Aspects of the Electrocatalytic Oxygen Evolution Reaction over Ni-Co Oxides ChemElectroChem 6 5588-95

[57] Lee K-G, Balamurugan M, Park S, Ha H, Jin K, Seo H and Nam K T 2019 Importance of Entropic Contribution to Electrochemical Water Oxidation Catalysis ACS Energy Lett. 4 1918-29

[58] Seo H, Park S, Cho K H, Choi S, Ko C, Randriamahazaka H and Nam K T 2021 Complex Impedance Analysis on Charge Accumulation Step of Mn304 Nanoparticles during Water Oxidation ACS Omega 6 18404-13

[59] Scholz J, Risch M, Stoerzinger K A, Wartner G, Shao-Horn Y and Jooss C 2016 Rotating Ring-Disk Electrode Study of Oxygen Evolution at a Perovskite Surface: Correlating Activity to Manganese Concentration J. Phys. Chem. C 120 27746-56

[60] Willems H, Kobussen A G C, De Wit J H W and Broers G H J 1984 The oxygen evolution reaction on cobalt: Part I. Reaction order experiments and impedance measurements J. Electroanal. Chem. Interfacial Electrochem. 170 227-42

[61] Castro E B and Gervasi C A 2000 Electrodeposited Ni-Co-oxide electrodes:characterization and kinetics of the oxygen evolution reaction Int. J. Hydrogen Energy 25 1163-70

[62] Kessler T, Triaca W E and Arvia A J 1994 Kinetics and mechanism of the oxygen evolution reaction at oxide-coated Co-Ni amorphous alloy electrodes J. Appl. 
Electrochem. 199424424 310-5

[63] Nikolov I, Darkaoui R, Zhecheva E, Stoyanova R, Dimitrov N and Vitanov T 1997 Electrocatalytic activity of spinel related cobalties $\mathrm{MxCo3}-\mathrm{xO} 4(\mathrm{M}=\mathrm{Li}, \mathrm{Ni}, \mathrm{Cu})$ in the oxygen evolution reaction J. Electroanal. Chem. 429 157-68

[64] Singh R N, Koenig J -F., Poillerat G and Chartier P 1990 Electrochemical Studies on Protective Thin $\mathrm{Co} 3 \mathrm{O} 4$ and NiCo2 $\mathrm{O} 4$ Films Prepared on Titanium by Spray Pyrolysis for Oxygen Evolution J. Electrochem. Soc. 137 1408-13

[65] Baumung M, Schönewald F, Erichsen T, Volkert C A and Risch M 2019 Influence of particle size on the apparent electrocatalytic activity of LiMn2O4 for oxygen evolution Sustain. Energy Fuels 3 2218-26

[66] Dionigi F and Strasser P 2016 NiFe-Based (Oxy)hydroxide Catalysts for Oxygen Evolution Reaction in Non-Acidic Electrolytes Adv. Energy Mater. 61600621 
Supporting Information

Calculation of the Tafel slope and reaction order of the oxygen evolution reaction in alkaline electrolytes for the adsorbate mechanism

Denis Antipin, Marcel Risch*

Nachwuchsgruppe Gestaltung des Sauerstoffentwicklungsmechanismus, Helmholtz-Zentrum Berlin für Materialien und Energie GmbH, Hahn-Meitner Platz 1, 14109 Berlin, Germany

* marcel.risch@helmholtz-berlin.de

\begin{tabular}{|l|l|}
\hline Index & Page \\
\hline Example of calculation & S2-S3 \\
\hline Figures & S4-S8 \\
\hline Tables & S9 \\
\hline
\end{tabular}

9 pages, 6 supporting figures, 2 supporting tables 


\section{Example of the Tafel slope calculation}

Assume first two steps (M1 and M2) of adsorbate mechanism (calculations for further steps were made similarly to them):

$$
\begin{array}{ll}
\text { M1 } & \underline{\mathrm{M}-\mathrm{OH}}+\mathrm{OH}^{-} \rightleftharpoons \underline{\mathrm{M}=\mathrm{O}}+\mathrm{H}_{2} \mathrm{O}+\mathrm{e} \\
\text { M2 } & \underline{\mathrm{M}=\mathrm{O}}+\mathrm{OH}^{-} \rightleftharpoons \underline{\mathrm{M}-\mathrm{OOH}}+\mathrm{e}
\end{array}
$$

Current density for the first reaction (M1) can be written as:

$j_{1}=I / A=n \cdot F \cdot r_{1}$

The reaction rate is equal to:

$r_{1}=k_{+1} \cdot a_{O H} \cdot \theta_{O H}$

As is was mentioned in the main text, we assumed surface coverage equal to $\theta_{O H}=1$ for the first step in the mechanism. For Tafel analysis a hydroxide activity of $a_{O H}=1$ was used.

Since the we first reaction is electrochemical, the expression for the kinetic constant has a form:

$k_{+1}=k_{+1}^{0} \cdot e^{(1-\alpha) \cdot f \cdot \eta}$

Combining Eqs. S1-S3, we formulate the final expression for the current density for the first forward step:

$j_{1}=n \cdot F \cdot k_{+1}^{0} \cdot e^{(1-\alpha) \cdot f \cdot \eta} \cdot a_{O H}$

Using values for $\mathrm{k}^{0}{ }_{+1}$ of 1 from Table 1 , we could plot voltammogram for the later Tafel analysis (Fig. 2a of main text).

If we consider second reaction (M2) as a RLS, an assumption of pre-equilibrated previous steps was used. It means, that the reaction rates of the forward and backward steps prior to RLS are equal:

$r_{1}=r_{-1}$

The reaction rate of the backward step $\mathrm{r}_{-1}$ can be written as:

$r_{-1}=k_{-1} \cdot a_{H_{2} O} \cdot \theta_{O}$

The expression for the kinetic constant has a form:

$k_{-1}=k_{-1}^{0} \cdot e^{-\alpha \cdot f \cdot \eta}$

Combining Eqs. S6-S7, the final expression for the reaction rate of the backward step can be written:

$r_{-1}=k_{-1}^{0} \cdot e^{-\alpha \cdot f \cdot \eta} \cdot a_{H_{2} O} \cdot \theta_{O}$

After a substitution of Eq. S2 and Eq. S8 in equality Eq. S5, we got first equation for surface coverages:

$k_{+1} \cdot a_{O H} \cdot \theta_{O H}=k_{-1}^{0} \cdot e^{-\alpha \cdot f \cdot \eta} \cdot a_{H_{2} O} \cdot \theta_{O}$

Second equation came from a fact that overall surface coverage is equal to 1 . For the first reaction $\mathrm{M} 1$ it has the following form:

$\theta_{O H}+\theta_{O}=1$

Solving system of two equations Eq. S9 and Eq. 10 with respect to $\theta_{O H}$ and $\theta_{O}$, final expression for the surface coverage were obtained:

$\theta_{\mathrm{OH}}=\frac{a_{\mathrm{H}_{2} \mathrm{O}}}{a_{\mathrm{H}_{2} \mathrm{O}}+\frac{k_{1}^{0}}{k_{-1}^{0}} \exp (f * \eta) * a_{\mathrm{OH}}}$ 
$\theta_{O}=\frac{\frac{k_{1}^{0}}{k_{-1}^{0}} \exp (f * \eta) * a_{O H}}{a_{H_{2} O}+\frac{k_{1}^{0}}{k_{-1}^{0}} \exp (f * \eta) * a_{O H}}$

(Eq. S12)

Akin to the first reaction, the current density and the reaction rate for the second one can be written as:

$j_{2}=I / A=n \cdot F \cdot r_{2}$

$r_{2}=k_{+2} \cdot a_{O H} \cdot \theta_{O}$

After combining Eqs. S10, S13-14, we got the final expression for the current density:

$j_{2}=n * F * k_{+2}^{0} * a_{O H} * \frac{\frac{k_{1}^{0}}{k_{-1}^{0}} \exp (f * \eta) * a_{O H}}{a_{\mathrm{H}_{2} \mathrm{O}}+\frac{k_{1}^{0}}{k_{-1}^{0}} \exp (f * \eta) * a_{O H}} * e^{(1-\alpha) * f * \eta}$

Using values for kinetic constants from Table 1, we could plot voltammogram for the later Tafel analysis (Fig. 2b of main text). 


\section{Figures}

a)

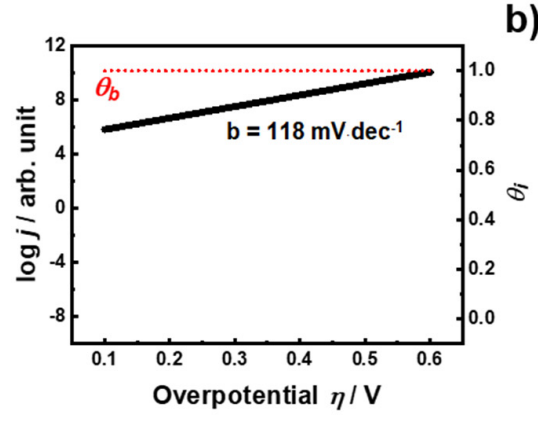

c)

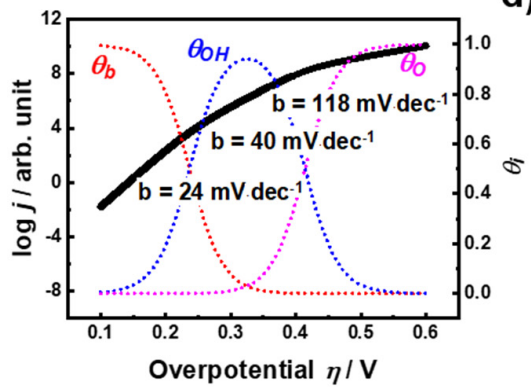

e)

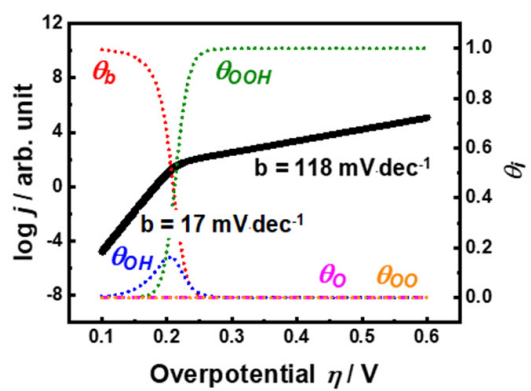

b)

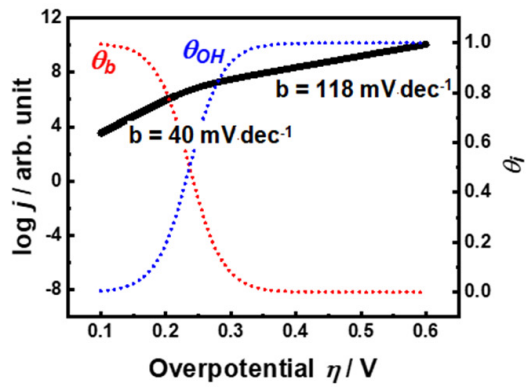

d)

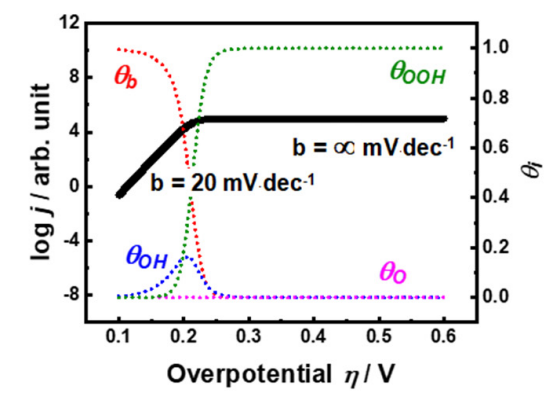

Fig. S1. Simulated Tafel plots assuming M5 as the initial step. Same set of kinetic constants (Table 1 of the main text) used for this Tafel plot, except $k_{-4}\left(10^{6}\right.$ instead of $10^{12}$, see Table S1). 
a)

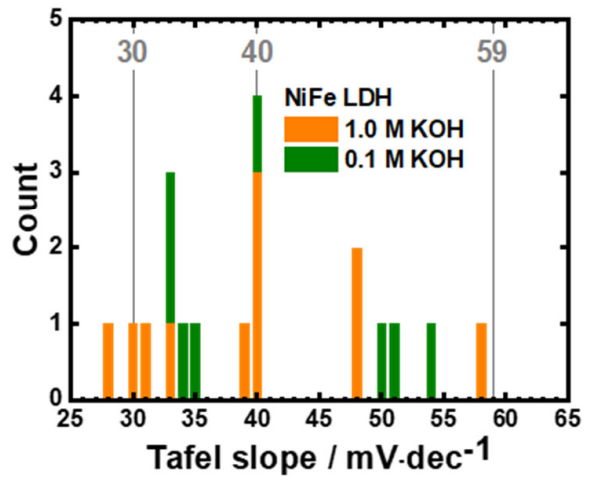

b)

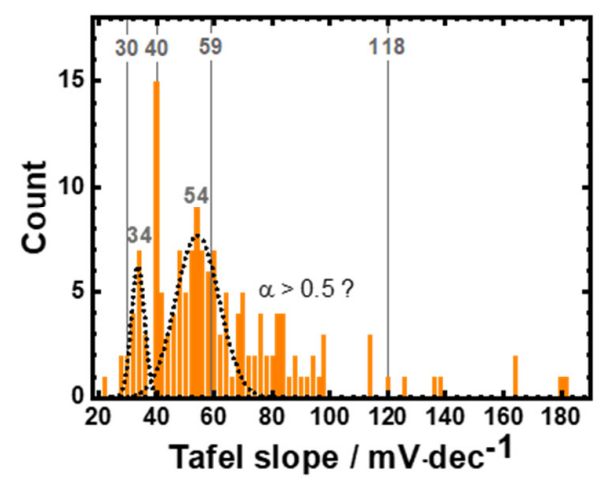

Fig. S2. (a) Histogram of Tafel slopes reported for NiFe LDH in $1.0 \mathrm{M}$ and $0.1 \mathrm{M} \mathrm{KOH}$. Binning width was $1 \mathrm{mV} / \mathrm{dec}$. Data taken from ref. [1]. (b) Histogram of Tafel slopes reported for various electrocatalyst. Data taken from [1-5]. Binning was $5 \mathrm{mV} / \mathrm{dec}$. The grey lines indicate common Tafel slopes assuming $\alpha=0.5$. 


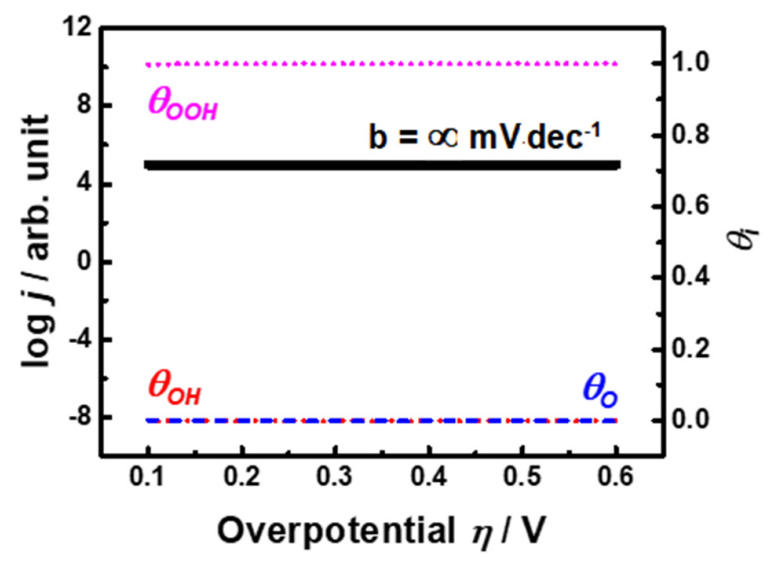

Fig. S3. Simulated Tafel plot assuming M3" step is RLS. Different set of kinetic constants (Table S2) used for this Tafel plot results in one dominant surface coverage and one Tafel slope.

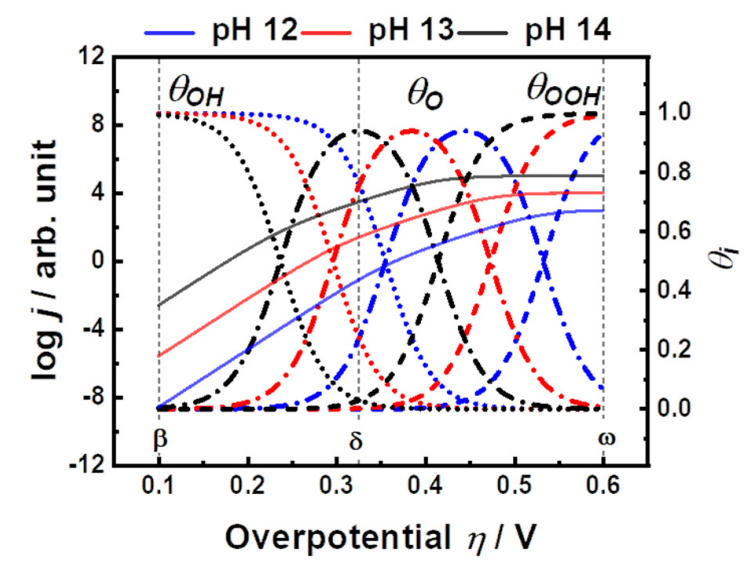

Fig. S4. Simulated Tafel plots between $\mathrm{pH} 12$ and 14 assuming $M 3$ as the RLS. The kinetic constants may be found in Table 1. All simulations use a transfer coefficient of $\alpha=0.5 . \beta, \delta$ and $\omega$ denote potentials of interest that are discussed in the main text. 
a)

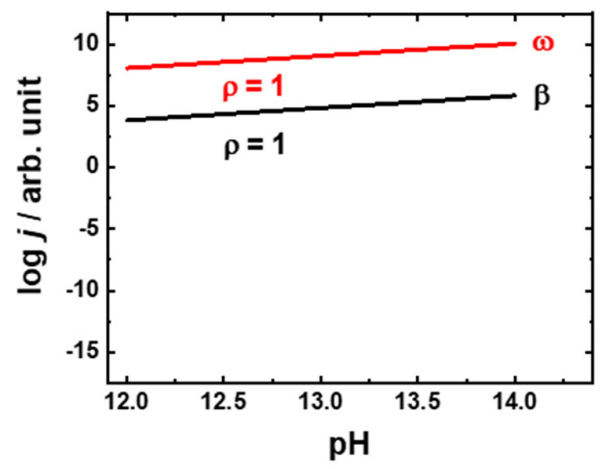

c)

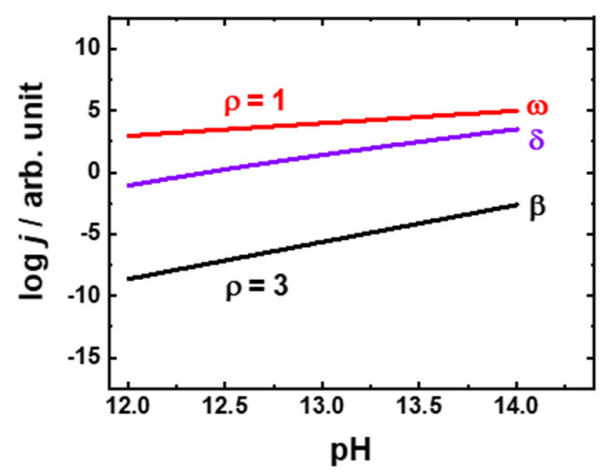

e)

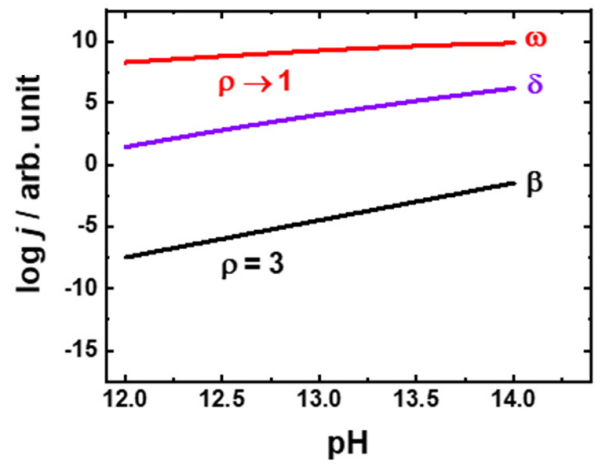

b)

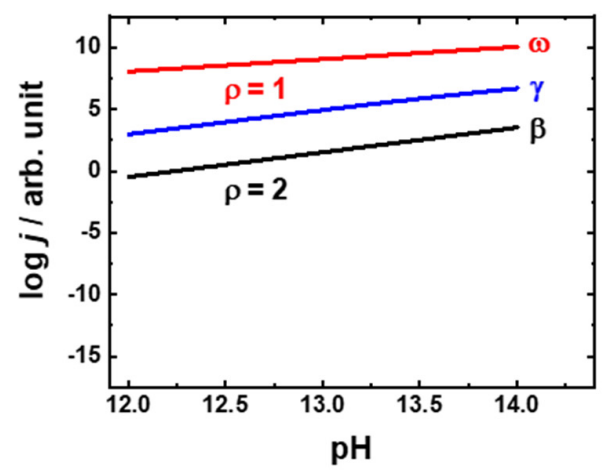

d)

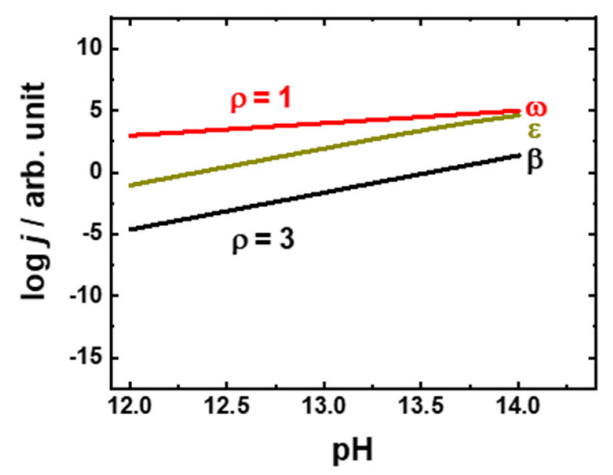

f)

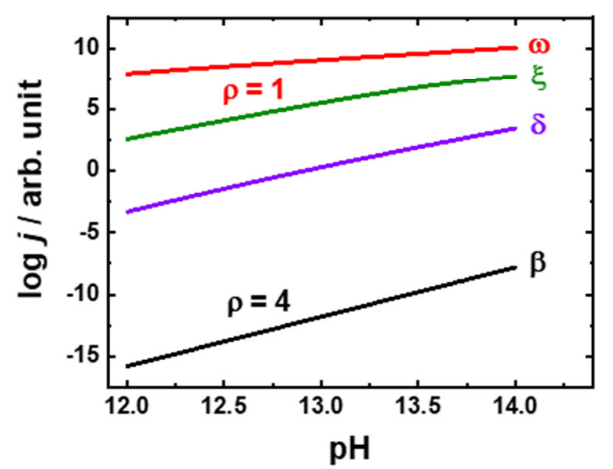

Fig. S5. Simulated current densities as function of $\mathrm{pH}$ at key potentials identified in Fig. 2 assuming the RLS of (a) M1, (b) M2, (c) M3, (d) M3', (e) M4 and (f) M5. M3 and M3' have the same RLS but were simulated with different sets of kinetic constants found in Table 1. All simulations use a transfer coefficient of $\alpha=0.5$. 
a)

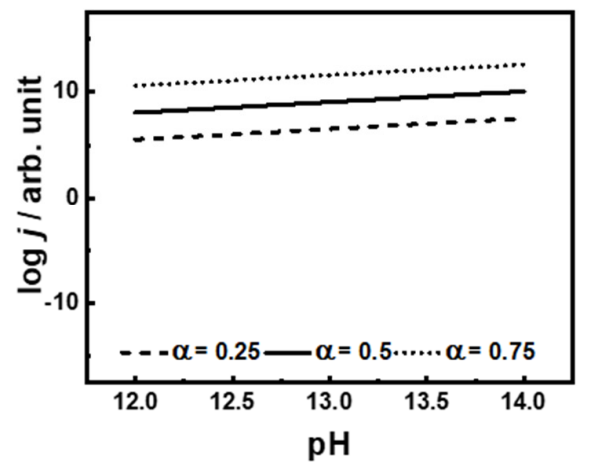

b)

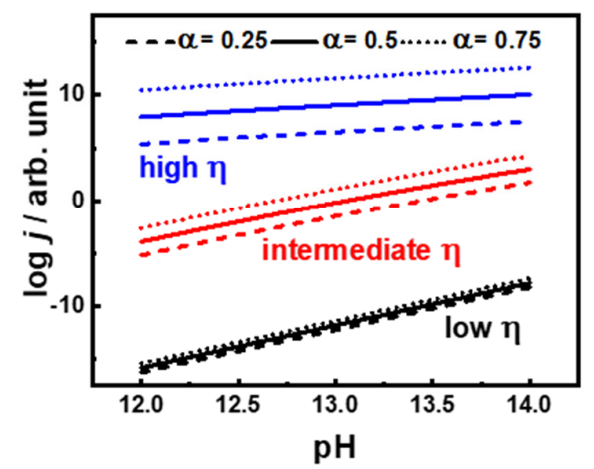

Fig. S6. Simulated log $j$ vs. pH plots assuming the RLS of (a) $M 1$ and (b) $M 5$ steps with different values of the transfer coefficient. 
Tables

Table S1. Values of kinetic constants used in the simulation for Fig. S1. The same mechanism with different step order (M5 - M4) was used for the simulations.

\begin{tabular}{|l|l|l|l|l|l|}
\hline \multirow{2}{*}{$\begin{array}{c}\text { Kinetic } \\
\text { constant }\end{array}$} & \multicolumn{6}{c|}{ Rate-limiting step } \\
\cline { 2 - 7 } & $\mathbf{M 5}$ & $\mathbf{M 1}$ & $\mathbf{M 2}$ & $\mathbf{M 3}$ & $\mathbf{M 4}$ \\
\hline$k_{+1}$ & 1 & $10^{3}$ & $10^{3}$ & $10^{3}$ & $10^{3}$ \\
\hline$k_{-1}$ & - & $10^{7}$ & $10^{7}$ & $10^{7}$ & $10^{7}$ \\
\hline$k_{+2}$ & - & 1 & $10^{3}$ & $10^{3}$ & $10^{3}$ \\
\hline$k_{-2}$ & - & - & $10^{10}$ & $10^{10}$ & $10^{10}$ \\
\hline$k_{+3}$ & - & - & 1 & $2 * 10^{12}$ & $2^{*} 10^{12}$ \\
\hline$k_{-3}$ & - & - & - & $10^{12}$ & $10^{12}$ \\
\hline$k_{+4}$ & - & - & - & 1 & 10 \\
\hline$k_{-4}$ & - & - & - & - & $10^{6}$ \\
\hline$k_{+5}$ & - & - & - & - & 1 \\
\hline$k_{-5}$ & - & - & - & - & - \\
\hline
\end{tabular}

Table S2. Values of kinetic constants used in the simulation for Fig. S3. M3 and M3" are the same rate-limiting step with different sets of constants

\begin{tabular}{|l|l|l|}
\hline \multirow{2}{*}{ Kinetic constant } & \multicolumn{2}{c|}{ Rate-limiting step } \\
\cline { 2 - 3 } & $\mathbf{M 3}$ & $\mathbf{M} \mathbf{3}^{\prime \prime}$ \\
\hline$k_{+1}$ & $10^{3}$ & $10^{3}$ \\
\hline$k_{-1}$ & $10^{7}$ & $10^{2}$ \\
\hline$k_{+2}$ & $10^{3}$ & $10^{3}$ \\
\hline$k_{-2}$ & $10^{10}$ & $10^{2}$ \\
\hline$k_{+3}$ & 1 & 1 \\
\hline$k_{-3}$ & - & - \\
\hline
\end{tabular}

\section{References}

[1] Dionigi F and Strasser P 2016 NiFe-Based (Oxy)hydroxide Catalysts for Oxygen Evolution Reaction in Non-Acidic Electrolytes Adv. Energy Mater. 61600621

[2] Yuan N, Jiang Q, Li J and Tang J 2020 A review on non-noble metal based electrocatalysis for the oxygen evolution reaction Arab. J. Chem. 13 4294-309

[3] Yu M, Budiyanto E and Tüysüz H 2021 Principles of Water Electrolysis and Recent Progress in Cobalt-, Nickel-, and Iron-Based Oxides for the Oxygen Evolution Reaction Angew. Chemie Int. Ed.

[4] Liu D, Zhou P, Bai H, Ai H, Du X, Chen M, Liu D, Ip W F, Lo K H, Kwok C T, Chen S, Wang S, Xing G, Wang $X$ and Pan H 2021 Development of Perovskite Oxide-Based Electrocatalysts for Oxygen Evolution Reaction Small 2101605

[5] Suen N-T, Hung S-F, Quan Q, Zhang N, Xu Y-J and Chen H M 2017 Electrocatalysis for the oxygen evolution reaction: recent development and future perspectives Chem. Soc. Rev. 46 337-65 